\title{
ANALISIS NARATOLOGIS SKANDAL AKSI KORUP PRESIDEN DONALD TRUMP DALAM SURAT KABAR DARING AMERIKA DAN INTERNASIONAL
}

\author{
Lestari Manggong \\ Departemen Susastra dan Kajian Budaya \\ Fakultas Ilmu Budaya, Universitas Padjadjaran \\ lestari.manggong@unpad.ac.id
}

\begin{abstract}
Abstrak
Skandal aksi korup Presiden Donald Trump menyeretnya ke pemakzulan yang diputuskan oleh Dewan Perwakilan Rakyat Amerika Serikat pada tanggal 18 Desember 2019. Tulisan ini membahas skandal aksi korup Presiden Trump sebagaimana dipaparkan dalam tiga kolom opini di koran daring The Washington Post, The Washington Times, dan Reuter. Dengan mengadaptasi analisis naratologis Berning (2011), pembahasan atas ketiga kolom opini tersebut dilakukan dengan cara menyikapi ketiga produk jurnalisme tersebut sebagai produk naratif, dengan memperhatikan jenis fokalisasi dan jenis narasinya. Tulisan ini pada akhirnya menyediakan simpulan berupa pandangan tentang bias politik dalam dua koran daring Amerika dan satu koran daring internasional tersebut tentang pemberitaan skandal aksi korup Presiden Trump.
\end{abstract}

Kata kunci: aksi korup, Presiden Tump, analisis naratologis, fokalisasi, bias politik

\begin{abstract}
President Donald Trump's corruption scandal brought him to his impeachment, settled by the House of Representatives of the United States of America on December 18, 2019. This essay discusses President Trump's corruption scandal as reported in three opinion columns in three online newspapers The Washington Post, The Washington Times, and Reuter.By adapting narratological analysis conducted by Berning (2011), the discussin on the three columns is practiced by treating the the three jornalism products as narrative products, by focusing on the types of focalisation and narration. This essay ultimately provides a conclusion regarding a view on political biases in the two American and one international online newspapers about President Trump's corruption scandal.
\end{abstract}

Keywords: corruption, President Trump, narratological analysis, focalisation, political bias

\section{PENDAHULUAN}

Tulisan ini muncul sebagai reaksi atas semakin maraknya pemberitaan dalam media berita daring Amerika dan internasional tentang pemakzulan Presiden Donald Trump. Terkait dengan ini, tulisan ini berfokus pada skandal aksi korup Presiden Trump dalam surat kabar (koran) daring Amerika dalam kolom opini The Washington Post dan The Washington Times. Kedua koran daring ini dipilih untuk dibahas dan 
dibandingkan atas dasar kecenderungan haluan politiknya; The Washington Post berhaluan politik kiri-tengah ${ }^{1}$, sementara The Washington Times berhaluan politik kanan-tengah ${ }^{2}$. Kolom opini tentang skandal aksi korup Presiden Trump dalam kedua koran daring tersebut juga akan dibandingkan dengan cara pandang media berita lain yang berhaluan politik relatif netral, yaitu koran daring internasional Reuter, yang haluan politiknya paling tidak bias ${ }^{3}$.

Dalam tulisan ini, pembahasan atas ketiga kolom opini tersebut dilakukan berlandaskan metode yang digunakan Berning (2011) yang menganalisis 25 reportase 4 jurnalistik dengan menyikapinya sebagai produk naratif. Sebagai produk naratif, ke-25 reportase yang dianalisis oleh Berning ditelaah menggunakan pendekatan naratologi Genette, Bal, Chatman, Price, dan Jahn. Dengan metode serupa, tulisan ini akan mengadaptasi cara analisis Berning dengan menerapkannya pada tiga produk jurnalisme pada kolom opini dalam koran daring yang disebutkan di atas. Berbeda dari Berning yang memfokuskan analisis pada empat kategori, yaitu: situasi naratif (narrative situation), urutan temporal (temporal order), ruang naratif (narrative space), dan karakterisasi (characterisation), tulisan ini hanya akan menelaah ketiga kolom opini dalam The Washington Post, The Washington Times, dan Reuter pada satu kategori saja, yaitu situasi naratif. Hal ini dilakukan atas dasar pertimbangan bahwa tulisan ini secara lebih spesifik akan menggarisbawahi dengan mekanisme apa saja bias haluan yang diimplikasikan dalam kolom-kolom opini tersebut dihadirkan.

Dalam pembahasannya, tulisan ini akan menyediakan penjabaran singkat tentang perkembangan aliran jurnalisme di Amerika yang akan mengerucut pada kemunculan gerakan Jurnalisme Baru (New Journalism movement) dengan merujuk pada Hellman (1981), Roggenkamp (2005), dan Berning (2011). Gerakan Jurnalisme Baru di Amerika perlu diberikan pengantarnya dalam tulisan ini karena gerakan inilah yang melandasi jenis produk jurnalisme yang hibrid, yang menggabungkan unsur naratif dan reportase. Pada bagian selanjutnya akan dijabarkan pengantar tentang aksi suap dalam tradisi Amerika, dengan pertama-tama mengedepankan perbedaan konsepsi tentang istilah aksi korup dan tindakan korupsi di Indonesia dan Amerika, yang merujuk pada pengamatan Teachout (2014).

Bagian pengantar ini akan berujung pada penjabaran definitif tentang apa yang dimaksud dengan jenis aksi korup yang disebut quid pro quo dalam konteks hukum di Amerika. Bagian selanjutnya akan masuk ke pembahasan tentang ketiga kolom opini skandal aksi korup Presiden Trump, yang menggunakan metode analisis naratologis. Bagian terakhir tulisan ini akan menyediakan simpulan berupa pandangan tentang bias politik dalam The Washington Post, The Washington Times, dan Reuter tentang pemberitaan skandal aksi korup Presiden Trump.

\footnotetext{
1Sumber: https://mediabiasfactcheck.com/washington-post/(Diakses 26 Desember 2019).

2Sumber: https://mediabiasfactcheck.com/washington-times/(Diakses 26 Desember 2019).

3Sumber: https:// mediabiasfactcheck.com/reuters/(Diakses 26 Desember 2019).

${ }^{4} \mathrm{Ke}-25$ reportase ini dinominasikan dalam kategori ‘Beste Reportage 2009' (Reportase Terbaik Tahun 2009) dalam penghargaan Deutscher Reporterpreis (Penghargaan Reporter Jerman). Nominasi untuk kategori ini terdiri atas 14 reportase dalam majalah, 6 surat kabar, dan 5 suplemen (Berning, 2011).
} 


\section{METODE PENELITIAN}

Metode yang digunakan untuk penelaahan ini adalah metode analisis naratologis yang sebelumnya pernah digunakan oleh Berning (2011), yang menganalisis 25 reportase jurnalistik di Jerman dengan menyikapinya sebagai produk naratif. Dengan mengadaptasi Berning, tulisan ini akan menganalisis tiga kolom opini dalam The Washington Post, The Washington Times, dan Reuter denganmemfokuskan pada kategori situasi naratif. Situasi naratif, menurut pengamatan Berning yang merujuk pada para strukturalis kajian naratologi seperti Brooks dan Warren (1959), Friedman (1955), Booth (1961), dan Romberg (1962), secara umum berarti sudut pandang. Berning menjabarkan bahwa situasi naratif ditelaah berdasarkan jenis fokalisasi; fokalisasi eksternal atau internal, dan juga jenis narasi; narasi homodiegetik atau heterodiegetik.

Merujuk pada kata dasar "focal" yang berarti lensa, dalam naratologi istilah fokalisasi dimaknai sebagai sudut pandang penceritaan. Dalam rumusan Genette (1980), fokalisasi mengekspresikan rasio pengetahuan antara narator dan karakter dalam cerita. Fokalisasi, secara konseptual, berdasarkan perspektif fungsional, dapat dimaknai sebagai alat yang membatasi informasi naratif. Dengan demikian, maka dalam narasi yang berfokalisasi eksternal, rasio pengetahuan narator terbatas pada apa yang dilihatnya dari luar, bukan dari diri karakter, seperti halnya kamera yang menyorot pemandangan di hadapannya. Sebaliknya, dalam narasi yang berfokalisasi internal, rasio pengetahuan narator setara dengan rasio pengetahuan karakter, karena cerita dinarasikan dari lensa narator yang di luar diri karakter dan juga narator yang masuk ke dalam diri karakter.

Perbedaan jenis narasi, yaitu homodiegetik dan heterodiegetik, dapat terlihat dari jenis fokalisasi yang teridentifikasi dalam naratif. Merujuk pada Genette (1980), suara narator, atau cara cerita dipersepsi oleh narator, dikategorikan menjadi dua, yaitu: homodiegetik dan heterodiegetik. Narator homodiegetik adalah narator yang hadir sebagai karakter dalam cerita. Sedangkan narator heterodiegetik adalah narator yang absen (tidak hadir) dalam cerita. Narasi disebut homodiegetik jika dalam naratifnya tampak bahwa fokalisasinya internal. Sementara, narasi disebut heterodiegetik jika dalam naratifnya tampak bahwa fokalisasinya internal dan eksternal. Perbedaan jenis narasi inilah yang melandasi bias politik yang terdapat dalam ketiga kolom opini yang ditelaah. Dalam pembahasan, bias politik ini menjadi penting untuk dicermati karena menunjukkan gejala sentimen tertentu (negatif, positif, maupun netral) terhadap aksi korup Presiden Trump.

\section{HASIL DAN PEMBAHASAN}

\subsection{Antara Fiksi dan Fakta: Pengantar Singkat Jurnalisme Baru di Amerika}

Gerakan Jurnalisme Baru mencapai popularitasnya di Amerika di pertengahan tahun 1960-an (Berning, 2011: 18). Tujuan dari gerakan ini adalah "to create authentic pieces and to convey a feeling of immediacy to the reader" (Berning: 38). Merujuk pada Wolfe dan Johnson (1973), Berning mencatat bahwa para Jurnalis Baru "copied techniques employed in the realist novel and used these stylistic devices in order to engage the reader both intellectually and emotionally" (Berning: 39). Secara historis, sesungguhnya istilah Jurnalisme Baru telah mengemuka sejak akhir abad ke-19 di Amerika. Aliran 
jurnalisme yang sifatnya menggabungkan unsur naratif dan reportase yang mengombinasikan unsur fiksi dan fakta ini mengemuka pada masa itu karena munculnya kebutuhan untuk membuat berita dalam koran cetak menjadi lebih menarik untuk dibaca. Semakin banyak orang yang tertarik untuk membacanya, maka semakin tinggilah oplah penjualan koran tersebut. Pengamatan Roggenkamp (2005) menunjukkan bahwa cara baru menarasikan berita yang kemudian dikenal dengan Jurnalisme Baru telah ada sejak terjadinya persaingan antara tiga surat kabar di New York, yaitu Sun, World, dan Journal. Sebagai dampak dari persaingan tersebut, istilah Jurnalisme Baru yang diperkenalkan oleh Matthew Arnold di tahun 1887 kemudian didefinisikan sebagai "an innovative, commercialized, sensationalistic, and above all dramatic style of reportage" (Roggenkamp: xii). Istilah ini juga muncul sebagai dampak dari gaya editorial yang dipraktikkan Joseph Pulitzer pada masa itu. Terobosan baru inilah yang kemudian mengangkat nama Pulitzer, yang hingga kini dijadikan sebagai nama penghargaan prestisius bidang jurnalistik di Amerika. Aliran baru ini memercikkan pro dan kontra. Di satu sisi, gaya penulisan jurnalistik semacam ini dapat menguntungkan bisnis surat kabar, namun di sisi lain, gaya ini berpotensi mendeviasi kebenaran faktual sebuah berita.

Di awal kemunculannya, praktik Jurnalisme Baru banyak dikritik karena, seperti yang disampaikan Roggenkamp,

[r]eporters and editors rewrote current events into stories laced with the familiar motifs of hoaxes, scientific and travel adventures, mystery and detective tales, and historical romances, to name just a few genres, in effect revising and resurrecting these popular fictional forms as news items (2005: xii).

Kecenderungan ini muncul karena narasi bergenre ilmiah, petualangan, misteri, cerita detektif, dan kisah romantis historis sedang populer pada masa itu. Hal ini mengakibatkan

reporters fashioned their own dramas based on those that readers recognized from a broadly drawn literary culture, and they populated these dramas with such rich character types as the female adventurer, the accused murderer, the dashing hero, and the damsel in distress (Roggenkamp, 2005: xv-xvi).

Akan tetapi, berbeda dari karya fiksi, produk Jurnalisme Baru ini berpotensi menjadi lebih menarik, karena materi dasar kronologi berita yang disampaikan adalah nyata, bukan rekaan.

Para penulis kanon Amerika di abad ke-19 seperti William Dean Howells, Stephen Crane, Mark Twain, Theodore Dreiser, and Ernest Hemingway memulai karir menulisnya sebagai jurnalis (Roggenkamp, 2005: xv). Latar ini pulalah yang menyebabkan aliran Jurnalisme Baru semakin mengemuka di Amerika pada masa itu. Menanggapi kemunculan aliran ini, para jurnalis konservatif menentangnya dan menyebutnya semata-mata "highly amusing stories" dan "outright falsification" (Roggenkamp, 2005: 120). 
Tidak dapat dipungkiri, Jurnalisme Baru menjadi manipulatif karena dipraktikkan atas dasar kompetisi untuk merebut banyak pembaca, ditengah-tengah lakunya produk karya sastra yang sedang populer pada masa itu. Selain itu, manipulasi yang dilakukan juga adalah membaurkan batas fakta dan fiksi, yang dalam hal ini membahayakan karena akan membelokkan fakta yang ada (Roggenkamp: 137). Bagaimanapun, pada akhirnya, Jurnalisme Baru di akhir Abad ke-19 Amerika "stood as its own type of realism and operated under its own set of aesthetics, as it does today" (Roggenkamp: 137).

Dalam pengamatan yang lain, Hellman (1981) mencatat bahwa "[n]ew journalistic works share a factual subject matter and anaesthetic form and purpose" (Hellman: 24). Hellman berpendapat bahwa Jurnalisme Baru dapat dipahami sebagai genre sastra, karena, menurutnya, "[l]ike realistic fiction or romantic fiction or fabulist fiction, it has an aesthetic form and purpose making its "final direction" inward" (Hellman, 1981: 24).

Hellman berargumentasi bahwa Jurnalisme Baru adalah genre fiksi yang teksnya mengarah ke dalam, namun pada saat yang sama juga mengarah keluar, ke dunia aktual. Menurut Hellman, dalam Jurnalisme Baru, tidak ada penyimpangan yang dilakukan terhadap dunia aktual tersebut. Hanya saja bentuk autorialnya yang spekulatif dan fantastis, yang sudah jelas di mata pembacanya. Intinya, dunia yang ditunjuk adalah dunia jurnalistik yang bersumber pada sumber-sumber primer yang diperoleh dari hasil observasi langsung maupun kumpulan observasi yang dilakukan jurnalis lain (Hellman: 27). Hellman kemudian menutup argumentasinya dengan menyatakan bahwa "like any writing, new journalism points to an external subject; but, like traditional novels, romances, fabulations, and historical novels, it is fiction because it finally points to its own form" (Hellman: 33). Dengan kata lain, Jurnalisme Baru tetap memiliki unsur faktual di dalamnya, sekalipun ia ditulis dengan gaya penulisan yang mengikuti konvensi karya fiksi.

\subsection{Aksi Korup dalam Tradisi Amerika}

[W] hen a long train of abuses and usurpations, pursuing invariably the same Object evinces a design to reduce the under absolute Despotism, it is their right, it is their duty, to throw off such Government, and to provide new Guards for their future security (Deklarasi Kemerdekaan Amerika Serikat, 1776). ${ }^{5}$

Amerika adalah negara besar yang didirikan berlandaskan prinsip-prinsip dasar yang tertulis dalam Deklarasi Kemerdekaan Amerika Serikat di tahun 1776 yang disepakati oleh para patriot pendiri negara Amerika Serikat dari 13 negara bagian. Kondisi yang dideskripsikan dalam epigraf di atas merupakan landasan kuat yang digunakan para patriot pendiri negara Amerika Serikat untuk mendeklarasikan negaranya demi membebaskan diri dari kuasa Inggris. Dalam konteks kini, kondisi tersebut mirip dengan yang terjadi di Amerika pasca terpilihnya Donald Trump sebagai Presiden Amerika Serikat di akhir tahun 2016. Puncak dari reaksi keras menentang kepemerintahan Presiden Trump yang berciri

5Sumber: https://www.ushistory.org/declaration/document/ (Diakses 1 November 2019). 
mirip dengan yang dideskripsikan dalam epigraf tersebut adalah pemakzulan yang diputuskan oleh Dewan Perwakilan Rakyat Amerika Serikat pada Rabu, 18 Desember 2019.

Masa-masa awal kepemerintahan Presiden Trump diramaikan oleh tudingan tentang kecurangan yang dilakukan tim sukses Trump untuk dapat memenangkan pemilihan umum. Ia dituding telah bekerjasama dengan pemerintah Rusia untuk memengaruhi dan menggiring opini masyarakat Amerika agar cenderung memilih Trump sebagai Presiden mereka. Bukan hanya itu, pemerintah Rusia juga dikaitkan dengan kasus peretasan domain surel pribadi Hillary Clinton - rival politik Trump untuk keperluan kenegaraan, di masa jabatannya sebagai Menteri Luar Negeri Amerika Serikat. Aksi penggiringan opini dan upaya penjatuhan nama baik Hillary Clinton yang dilakukan Trump selama kampanye kepresidenannya merupakan wujud tindak penyelewengan kekuasaan (usurpation) yang disebutkan dalam kutipan deklarasi kemerdekaan di atas.

Presiden Trump dimakzulkan oleh Dewan Perwakilan Rakyat Amerika Serikat atas dua klausul: penyalahgunaan jabatan dan wewenang serta obstruksi Kongres pemerintah Amerika Serikat. Klausul pertama dilandasi oleh bukti yang menunjukkan bahwa Presiden Trump menggunakan jabatan dan wewenangnya sebagai Presiden Amerika Serikat untuk meminta pemerintah Ukraina melakukan investigasi atas putra dari Joe Biden, rival politik Presiden Trump untuk pemilihan Presiden tahun 2020 mendatang, yang menunjukkan cacat yang dilakukan putra Biden agar Biden tercoreng nama baiknya. Klausul kedua dilandasi oleh berbagai upaya yang dilakukan Presiden Trump untuk menghalang-halangi penyelidikan yang dilakukan oleh Kongres. ${ }^{6}$ Klausul pertama mengindikasikan bahwa Presiden Trump melakukan aksi korup, karena ia terbukti meminta bantuan dari pemerintah Ukraina dengan imbalan pencairan bantuan militer untuk pemerintah Ukraina sebesar \$391 juta. Terkait dengan klausul yang pertama ini, tulisan ini akan membahas skandal aksi korup quid pro quo yang dilakukan Presiden Trump. Secara umum, quid pro quo dapat diartikan sebagai tindakan timbal balik yang pada intinya memberikan seseorang apa yang diinginkannya, dengan syarat orang diberi hadiah tersebut memberikan apa yang kita inginkan. ${ }^{7}$ Dalam konteks hukum, tindakan ini dikategorikan sebagai aksi korup.

Dalam kosa kata bahasa Indonesia, tindakan korupsi sebagai akibat dari aksi korup didefinisikan sebagai "penyelewengan atau penyalahgunaan uang negara (perusahaan, organisasi, yayasan, dan sebagainya) untuk keuntungan pribadi atau orang lain" (KBBI daring). ${ }^{8}$ Ini menyebabkan tindakan korupsi kerap diasosiasikan dengan aksi curang menyelewengkan uang pihak tertentu demi keuntungan sendiri ataupun pihak lain. Keterlibatan uang dalam konteks definisi ini olehkarenanya menjadi vital. Sementara, sebagai pembanding, kata korupsi dalam kosa kata bahasa

6Perolehan suara untuk klausul pertama adalah 230 banding 197, yang didominasi suara terbanyak dari Partai Demokrat. Sementara perolehan suara untuk klausul kedua adalah 229 banding 198, yang juga didominasi suara terbanyak dari Partai Demokrat. Sumber: https://www.nytimes.com/2019/12/18/us/politics/trump-impeached.html (Diakses 26 Des 2019). 7Sumber: https://www.nytimes.com/2019/11/20/us/politics/quid-pro-quo.html (Diakses 26 Des 2019). 8Sumber: https://kbbi.kemdikbud.go.id/entri/korupsi (Diakses 26 Desember 2019). 
Inggris didefiniskan sebagai "dishonest or illegal behavior especially by powerful people (such as government officials or police officers)" (Merriam-Webster daring). Dari definisi tersebut, terlihat bahwa yang ditekankan adalah sikap curang ataupun ilegal yang dilakukan oleh orang-orang yang berkuasa. Dalam definisi tersebut, tampak bahwa tindakan ini tidak mutlak diasosiasikan dengan aksi menyelewengkan uang. Terkait dengan ini, Teachout (2014: 2) mencatat bahwa "[c]orruption, in the American tradition, does not just include blatant bribes and theft from the public till, but encompasses many situations where politicians and public institutions serve private interests at the public's expense." Atas dasar inilah maka dalam tulisan ini, dalam konteks tradisi Amerika, pembahasan tentang korupsi, atau lebih tepatnya aksi korup, merujuk pada definisi yang kedua.

Aksi korup quid pro quo yang ditudingkan kepada Presiden Trump merupakan sebuah pelanggaran yang menjadi landasan kuat pemakzulannya. Dalam sejarah Amerika, hingga Trump, telah ada tiga Presiden yang dimakzulkan. Yang pertama, Presiden ke-17 Amerika Serikat, Andrew Johnson, dimakzulkan karena ia menyalahgunakan wewenangnya sebagai Presiden dalam hal mengganti pejabat pemerintah federal tanpa mengonsultasikannya terlebih dahulu dengan senat. Yang kedua, Presiden ke-42 Amerika Serikat, Bill Clinton, dimakzulkan karena ia berbohong tentang skandal hubungannya dengan Monica Lewinsky. Pelanggaranpelanggaran yang ditudingkan dan berhasil dibuktikan tersebut mengandung arti "dishonest and illegal behavior" yang tertera dalam definisi tentang korupsi di atas. Tindakan korupsi yang dilakukan jelas tidak berasosiasi dengan uang, namun lebih dengan sikap menyeleweng. Serupa dengan dua Presiden pendahulunya, aksi korup quid pro quo yang ditudingkan kepada Presiden Trump juga merupakan pelanggaran yang mencerminkan sikap menyeleweng tersebut.

Teachout (2014) mencatat bahwa asal mula aksi korup dalam sejarah pemerintahan Amerika dapat ditelusuri sejak tahun 1785, ketika Benjamin Franklin, sepulangnya dari kunjungan kenegaraan ke Prancis, dihadiahi kotak tembakau mewah bertahtakan berlian, dari Raja Louis XVI. Di Eropa, pemberian semacam ini memiliki asosiasi positif tentang koneksi kedua negara dan citra elegan Prancis. Sebaliknya, di Amerika, pemberian tersebut menjadi problematis karena dapat dimaknai sebagai simbol persahabatan kedua negara, korupsi versi dunia lama (Eropa Barat), gestur hormat, atau aksi suap. Bagi bangsa Amerika, pemberian tersebut menyimbolkan bujukan, kebergantungan, kemewahan, dan ketidakpahaman bangsa Eropa tentang hubungan yang pantas antara politik, kekuasaan, dan persahabatan (Teachout: 1-2). Problematika yang muncul akibat hadiah tersebut, menurut Teachout, "demonstrated the belief that temptation and influence work in indirect ways, and that corruption is not merely transactional, or "quid pro quo," as it is sometimes called" (Teachout: 4). Ini berarti bahwa tindakan memberi hadiah berpotensi mengimplikasikan aksi suap ataupun menabung hutang budi kepada pihak yang diberikan karena adanya godaan dan pengaruh tersebut. Karena ini pulalah maka gestur memberi dan menerima hadiah menjadi sangat politis.

Teachout menyatakan kekhawatirannya tentang apa yang dihadapi Amerika saat ini, yaitu oligarki, sebuah kelompok penguasa yang memiliki kendali dominan atas sebuah negara. Menurut Teachout, oligarki akan tetap ada selama pemerintah 
Amerika tidak mengubah struktur fundamental relasi uang dan kuasa legislatif (2014: 16). Tampaknya inilah yang terjadi di masa kepemimpinan Presiden Trump. Sebagai sosok populis (Manggong, 2017), maka tidak mengherankan jika Presiden Trump dipersepsi sebagai figur pemimpin yang korup, karena "[c]orruption, corrupt, and related words were a major part of the grammar of the populists and the progressive reformers and were accusations that supported the rise of prosecutorial post-Watergate culture" (Teachout, 2014: 5).

\subsection{Analisis Naratologis Aksi Korup Presiden Donald Trump dalam The Washington Post, The Washington Times, dan Reuter}

Dalam kolom opininya, Greg Sargent, kolumnis koran daring The Washington Post mengemukakan persepsinya tentang betapa luasnya aksi korup yang terjadi di jajaran pejabat tinggi administrasi Presiden Trump, terkait dengan skandal Ukraina. Dengan judul “The Scope of Trump's Corruption is Mind-boggling: New Developments Show How", Sargent memaparkan bukti-bukti yang memberatkan tudingan yang ditujukan kepada Presiden Trump atas aksi korupnya. Dimuat pada tanggal 5 November 2019, ketika proses pemakzulan Presiden Trump sedang berada dalam tahap awal, kolom opini ini dibuka dengan afirmasi bahwa hingga saat itu, efek gurita skandal Ukraina - yang pada intinya merupakan permintaan bantuan yang dilakukan Presiden Trump terhadap Presiden Ukraina, Volodymyr Zelenskiy, untuk melakukan investigasi terhadap perusahaan yang dipimpin oleh putra dari Joe Biden, Hunter Biden - telah jelas. Secara naratologis, afirmasi yang memaparkan bukti-bukti tersebut masuk dalam kategori fokalisasi eksternal, karena rasio pengetahuan narator (dalam hal ini Sargent) terbatas pada apa yang dilihatnya dari luar. Seperti halnya kamera yang menyorot pemandangan di hadapannya, Sargent dalam bagian pembukanya ini hanya memaparkan bukti-bukti yang selama ini dipantaunya. Atas dasar ini, maka jenis narasi pada bagian ini merupakan narasi heterodiegetik.

Setelah pembuka ini, kolom Sargent menekankan bahwa ada dua aspek dari skandal tersebut yang perlu dielaborasi: 1.) skala yang diakibatkan dari skema skandal tersebut menyebabkan banyak agen pemerintah menjadi korup dan secara langsung menempatkan mereka dalam skenario upaya pemilihan kembali Trump di periode berikutnya, dan 2.) dua tujuan utama skema skandal tersebut-membuat Ukraina memvalidasi sebuah konspirasi teori yang menghapus kabar sabotase yang dilakukan Rusia di Pemilihan Presiden 2016 dan menjatuhkan rival politiknya, Joe Biden - adalah setali tiga uang. Sargent kemudian menambahkan: "At the core of this narrative is Trump's continuing reliance on foreign help in corrupting our democracy to his advantage, through two presidential elections, and the covering up of all of it" (Sargent, 2019). Dalam pernyataan tersebut Sargent mengaitkan kebergantungan Trump dengan negara asing dengan aksi korup dan demokrasi di Amerika.

Aksi Trump dalam pernyataan ini bersifat racun karena menyebabkan demokrasi Amerika menjadi korup. Sargent juga menuding Presiden Trump menutup-nutupi aksinya. Secara naratologis, hal-hal yang dijabarkan dalam bagian ini masuk dalam kategori fokalisasi internal, karena rasio pengetahuan narator (Sargent) disetarakan dengan rasio pengetahuan karakter (dalam hal ini Trump). Penyetaraan rasio pengetahuan Sargent dan Trump menghasilkan narasi yang 
memiliki tendensi menyudutkan Trump, karena narator membangun kesan bahwa aksi Trump merupakan penyebab korupnya demokrasi Amerika. Dengan perkataan lain, opini personal Sargent dalam hal ini dibuat menjadi faktual. Atas dasar ini, maka jenis narasi pada bagian ini merupakan narasi homodiegetik.

Pada bagian selanjutnya, Sargent memaparkan ulah korup yang dilakukan Presiden Trump berdasarkan reportase dari sumber lain, yaitu koran daring The New York Times, yang juga berhaluan politik kiri-tengah. ${ }^{9}$ Pemaparan yang dilakukan Sargent tampak objektif, karena semua informasinya direportase melalui perspektif fokalisator eksternal, layaknya kamera yang sedang menyorot peristiwa yang terjadi di hadapannya, tanpa disisipi pendapat pribadi. Karena pemaparannya terkesan objektif, maka fokalisasi dalam bagian ini bersifat eksternal. Atas dasar ini, maka jenis narasi pada bagian ini merupakan narasi heterodiegetik.

Di bagian selanjutnya, Sargent memaparkan keterlibatan William P. Barr - Jaksa Agung Amerika Serikat dan juru bicara nasonal untuk Komite Nasional Partai Republik - dalam skema tersebut, karena ia menutup-nutupi alasan sesungguhnya Presiden Trump menghubungi Presiden Zelenskiy. Sargent kemudian mengutarakan sebuah spekulasi: "At the end of all this, Barr actually might end up both helping to validate the conspiracy theory falsifying Russia's 2016 crimes and lending legitimacy to Trump's corrupt pressure on Ukraine to do the same" (Sargent, 2019). Dengan perkataan lain, sebagai kaki tangan Presiden Trump, Barr juga sama bersalahnya. Spekulasi yang dilakukan oleh narator (Sargent) membuat bagian naratif ini tampak subjektif, karena spekulasi yang dibangun dilandasi oleh praduga personal narator. Secara naratologis, karena bagian ini spekulatif, maka kategori fokalisasinya adalah fokalisasi internal. Atas dasar ini, maka jenis narasi pada bagian ini merupakan narasi homodiegetik.

Lebih lanjut lagi, narator bahkan menambahkan bahwa peran Barr sangat menentukan, karena di tangannyalah keabsahan aksi yang dilakukan Presiden Trump ditentukan. Tidak berhenti sampai di situ, Sargent menutup kolomnya dengan pernyataan:

We still haven't gotten our arms around the mind-boggling scale of corruption on display here. Multiple government agencies are actively helping Trump absolve Russia of sabotaging the last presidential election on his behalf-thus burying his own campaign's eagerness to benefit from it - and helping him cover up his effort to solicit more foreign help in cheating his way to victory in the next one (Sargent, 2019).

Pernyataan penutup tersebut mengimplikasikan bahwa skala efek gurita skandal Ukraina yang dilakukan Presiden Trump sedemikian besarnya sehingga melibatkan banyak agen pemerintah yang juga menyebabkan mereka korup. Bagian akhir ini jelas sangat subjektif dan karenanya berfokalisasi internal, karena narator sekali lagi membaurkan rasio pengetahuannya dengan rasio pengetahuan karakter

9Sumber: https:// mediabiasfactcheck.com/new-york-times/ (Diakses 30/11/2019). 
(Trump) yang secara eksplisit dicap curang oleh narator. Atas dasar ini, maka jenis narasi pada bagian ini merupakan narasi homodiegetik.

Dalam kolom opininya, Thomas Jipping, kolumnis koran daring The Washington Times mengemukakan persepsinya tentang tidak adanya fakta yang dapat memberatkan tudingan aksi korup Presiden Trump. Dengan judul "Speeding towards Impeachment in the Absence of Facts", Jipping memaparkan argumentasinya tentang betapa tidak berdasarnya landasan pemakzulan yang ditujukan kepada Presiden Trump. Kolom ini dimuat pada tanggal 9 Desember 2019, sebulan setelah kolom opini Sargent dimuat, dan sembilan hari sebelum Dewan Perwakilan Rakyat Amerika memutuskan pemakzulan Presiden Trump. Jipping membuka opininya dengan menyatakan Partai Demokrat melandasi argumentasi pemakzulan Presiden Trump berdasarkan tudingan upaya Trump berkoalisi dengan pemerintah asing agar ia dapat dipilih kembali menjadi Presiden. Selanjutnya, Jipping mempermasalahkan apakah itu yang benar-benar dilakukan Presiden Trump. Menurutnya, sebelum menuding Trump melakukan aksi korup, yang perlu dibuktikan adalah apakah benar ia menghubungi Presiden Ukraina untuk tujuantujuan yang ditudingkan di atas? Apa yang sebenarnya dilakukan oleh Trump, itu yang harus dijawab. Secara naratologis, fokalisasi di awal bagian pembuka ini cenderung eksternal, karena narator (Jipping) hanya memaparkan tudingantudingan yang dikemukakan oleh Parta Demokrat. Atas dasar ini, maka jenis narasi pada bagian ini merupakan narasi heterodiegetik. Akan tetapi, pertanyaan retoris yang dikemukakan berikutnya menunjukkan kecenderungan penggiringan opini terhadap karakter yang sedang dibicarakan (dalam hal ini Trump).

Dalam bantahannya, versi kronologi yang dipaparkan oleh Jipping adalah sebagai berikut: Yang diketahui dan disepakati bersama adalah fakta bahwa Presiden Trump menahan bantuan militer ke Ukraina sebelum percakapan telepon antara dia dan Zelenskiy terjadi tanggal 25 Juli. Percakapan telepon tersebut, menurut Jipping intinya hanya menanyakan "this whole situation with Ukraine" terkait tuduhan campur tangan Ukraina dalam Pemilihan Presiden tahun 2016 dan menanyakan apakah Joe Biden memiliki andil dalam menghentikan penyelidikan tentang perusahaan yang salah satu anggota dewan direkturnya adalah Hunter Biden, putranya. Satu setengah bulan kemudian, Presiden Trump mencairkan bantuan militer ke Ukraina. Jipping bersikeras bahwa "[n]othing in that account, as far as it goes, amounts to an impeachable offense" (Jipping, 2019), karena tidak ada bukti yang menyertainya. Yang terjadi hanyalah simpulan-simpulan yang diambil dari rangkaian peristiwa yang satu dengan yang lainnya. Di awal bagian ini, sekali lagi, fokalisasinya tampak eksternal karena dalam narasinya narator murni memaparkan sebuah kronologi. Atas dasar ini, maka jenis narasi pada bagian ini merupakan narasi heterodiegetik. Di bagian berikutnya, fokalisasinya bergeser menjadi internal karena narator menyisipkan opini pribadinya, dengan menggarisbawahi bahwa tidak ada bukti yang menyertai tudingan yang ditujukan kepada Trump. Atas dasar ini, maka jenis narasi pada bagian ini merupakan narasi homodiegetik.

Setelah itu, di bagian selanjutnya, Jipping memaparkan pernyataan-pernyataan yang dilontarkan sejumlah perwakilan Partai Demokrat, profesor di bidang hukum dari Harvard dan Stanford yang intinya adalah bahwa tindakan yang dilakukan 
Trump merupakan pelanggaran. Yang cacat dari pernyataan-pernyataan tersebut adalah tidak adanya bukti yang mendukung. Jipping menyanggah:

Believing something, even fervently, does not make it true. Repeating it, even endlessly, does not make it true. To make the charge stick, the impeachment inquiry must produce actual evidence for Mr. Trump's specific, nefarious, impeachable intent to make Ukraine interfere in the 2020 presidential election. So far at least, it has failed to do so (Jipping, 2019).

Dengan kata lain, yang dipaparkan oleh Partai Demokrat hanyalah sentimen mereka terhadap Trump, teori, bukan bukti. Lebih lanjut, Jipping menguatkan argumentasinya dengan menyatakan bahwa segala sesuatu yang dilakukan Presiden yang berada dalam masa jabatan periode pertamanya dapat memengaruhi peluang dipilih atau tidaknya Presiden tersebut di periode berikutnya. Jipping bahkan mempertaruhkan propertinya di Utah jika ada yang dapat membuktikan bahwa itu tidak mungkin terjadi. Di akhir opininya, Jipping kembali menyerang dengan menghadirkan sebuah ironi; di permufakatan pertama yang beragenda utama pemakzulan Trump, Adam Schiff - Ketua Komite Intel Dewan Perwakilan Rakyat Amerika-memperingatkan perwakilan dari Partai Republik untuk tidak menjawab pertanyaan yang mengasumsikan fakta, bukan menunjukkan bukti. Sementara, ironisnya, yang terjadi adalah Schiff memutuskan pemakzulan Trump atas dasar asumsi dari fakta yang ada. Secara naratologis, bagian ini sarat dengan fokalisasi yang sifatnya internal, karena, sama seperti bagian yang sebelumnya, narator tampak menyisipkan opini pribadinya. Atas dasar ini, maka jenis narasi pada bagian ini merupakan narasi homodiegetik.

Berbeda dari Sargent dan Jipping, Andy Sullivan, dalam kolom opininya di koran daring internasional Reuters, yang berjudul "'No Quid Pro Quo': Trump's Defenses in the Impeachment Investigation", secara lebih objektif dan netral memaparkan fakta-fakta yang digunakan pihak Trump untuk menyanggah tudingan yang ditujukan kepadanya. Dalam kolom opininya, ada 10 fakta yang dipaparkan oleh Sullivan:

1. Trump mengatakan bahwa ia tidak meminta Presiden Zelenskiy untuk menginvestigasi Biden. Yang dilakukannya adalah menanyakan perihal korupsi yang merupakan endemik di Ukraina.

2. Naskah pembicaraan Trump di telepon dengan Zelenskiy menunjukkan bahwa Trump meminta Zelenskiy untuk menginvestigasi Biden.

3. Biden dan putranya menyangkal tudingan aksi korup yang ditujukan kepadanya ketika ia menjabat sebagai Wakil Presiden di era Obama, dan tidak ada bukti yang dapat menguatkan tudingan tersebut.

4. Trump meminta Zelenskiy mencermati teori konspirasi bahwa Ukraina, bukan Rusia, yang ikut campur dalam Pemilihan Presiden di tahun 2016.

5. Trump mengatakan ia tidak melakukan pelanggaran apapun dalam komunikasinya dengan Zelenskiy dengan merujuk pada kesaksian Gordon Sondland, Duta Besar Amerika Serikat untuk Uni Eropa dan juga sosok yang 
mendanai kampanye Trump, bahwa Trump tidak menginginkan quid pro quo dari pencairan bantuan militer untuk Ukraina.

6. Sondland bersaksi bahwa White House menolak mengundang Zelinskiy untuk bertemu dengan Trump untuk menekan Ukraina untuk melakukan investigasi yang diminta Trump.

7. Sondland berkata bahwa semua pejabat tingkat tinggi di administrasi Trump terlibat dalam agenda menekan Ukraina untuk kepentingan kampanye Trump.

8. Sondland secara bertahap meyakini bahwa White House menahan pencairan dana bantuan militer Amerika untuk Ukraina demi menekan Ukraina. Penahanan ini diamini oleh Mick Mulvaney, Kepala Staf White House. Namun Mulvaney kemudian menarik kembali pernyataannya.

9. Trump mengakui penahanan bantuan dana tersebut, namun dengan tujuan untuk menghindari Ukraina agar tidak terbelit masalah korupsi lagi.

10. Catatan dari percakapan telepon antara Trump dan Zelenskiy tidak mengindikasikan adanya agenda korupsi dari pihak Trump, dan Trump tidak mengungkit pembicaraan tersebut ketika keduanya bertemu di bulan April setelah Zelenskiy dilantik menjadi Presiden Ukraina.

Ke-10 fakta tersebut secara objektif dipaparkan, sepenuhnya dalam wujud reportase, tanpa ada penyisipan opini pribadi di antaranya. Secara naratologis, maka dapat dikatakan bahwa fokalisasi yang terlihat di sini jelas adalah murni fokalisasi eksternal. Atas dasar ini, maka jenis narasi pada bagian ini merupakan narasi heterodiegetik.

\section{PENUTUP}

Bias politik sebuah surat kabar dapat ditentukan oleh subjektifitas yang dihadirkan dalam reportasenya. Berning (2011: 42) mencatat bahwa cara penceritaan yang subjektif dalam reportase merujuk pada produk/teksnya (level ceritanya) dan proses/narasinya (level diskursusnya). Dalam konteks ini, level cerita kolom opini yang pertama jelas kontra Trump karena The Washington Post merupakan koran daring yang berhaluan kiri-tengah. Sebaliknya, level cerita kolom opini yang kedua jelas pro Trump karena The Washington Times merupakan koran daring yang berhaluan kanan-tengah. Level cerita dalam kolom ketiga, di sisi lain, tampak objektif karena tidak ada opini tertentu yang disisipkan. Dalam hal ini, koran daring internasional Reuter tampak konsisten menunjukkan posisinya sebagai surat kabar yang paling tidak bias. Dalam level diskursus, kolom opini yang pertama dan kedua menunjukkan gejala subjektif, sedangkan kolom opini yang ketiga menunjukkan gejala objektif.

Level diskursus kolom opini yang pertama memperlihatkan gejala subjektif karena meskipun kolom Sargent menggunakan fokalisasi eksternal karena ia sifatnya mereportase, namun pada saat yang sama, ketika kolom tersebut menghadirkan spekulasi, maka fokalisasi eksternalnya menjadi subjektif karena disisipi pandangan pribadi. Sementara itu, dengan mekanisme serupa, level diskursus kolom opini yang kedua juga memperlihatkan gejala subjektif karena meskipun kolom Jipping menggunakan fokalisasi eksternal karena ia sifatnya mereportase, namun pada saat yang sama, ketika kolom tersebut menghadirkan sanggahan, maka fokalisasi 
eksternalnya menjadi subjektif karena disisipi pandangan pribadi. Dalam kolom opini ketiga, level diskursusnya memperlihatkan gejala objektif, karena ia menggunakan fokalisasi eksternal heterodiegetik, dengan menghadirkan pernyataan-pernyataan luar dari berbagai sumber. Kolom opini ketiga tidak terlihat tendensius, karena ia tidak disisipi pandangan pribadi kolumnisnya.

Berdasarkan pengamatan tersebut, sebagai penutup, tulisan ini menyimpulkan bahwa dalam bidang jurnalisme, bias politik dapat terlihat dari jenis narasi yang terlihat dalam produk reportasenya. Dalam pengamatannya tentang perbedaan antara produk reportase Amerika dan Jerman, Berning (2011) menyimpulkan bahwa produk reportase Amerika cenderung menghadirkan narasi yang homodiegetik. Sebaliknya, produk reportase Jerman cenderung menghadirkan narasi yang heterodiegetik. Dalam kasus tiga koran daring yang dibahas dalam tulisan ini, kecenderungan jenis narasi homodiegetik kolom pertama dan kedua ditunjukkan melalui filterisasi fakta yang disampaikan oleh kolumnisnya. Sementara, dalam kolom opini ketiga jenis narasi heterodiegetik ditunjukkan melalui tidak adanya filterisasi fakta yang disampaikan oleh kolumnisnya. Bias politik The Washington Post, The Washington Times, dan Reuters yang berhaluan kiri-tengah, kanan-tengah, dan netral, olehkarenanya, dipengaruhi oleh tendensi-tendensi tersebut.

\section{DAFTAR PUSTAKA}

Berning, Nora. 2011. Narrative Meansto Journalistic Ends: A Narratological Analysis ofSelected Journalistic Reportages. Germany: VS VerlagfürSozialwissenschaften.

Fandos, Nicolas dan Michael D. Shear. 2019. “Trump Impeached for Abuse of Power and Obstruction of Congress" dalam The New York Times. https://www.nytimes.com/2019/12/18/us/politics/trump-impeached.html (Diakses 26 Desember 2019).

Genette, Gérard. 1980. Narrative Discourse: An Essay in Method. Ithaca, New York: Cornell University Press.

Hellman, John. 1981. Fables of Fact: The New Journalism as New Fiction. Urbana: University of Ilinois Press.

Jipping, Thomas. 2019. "Speeding toward Impeachment in the Absence of facts" dalam The Washington Times. https://www.washingtontimes.com/news/2019/dec/9/speeding-towardimpeachment-in-the-absence-of-fact/(Diakses 18 Desember 2019).

Korupsi. https:/ / kbbi.kemdikbud.go.id/entri/korupsi (Diakses 26 Desember 2019). Manggong, Lestari. 2017. “Konsep Demokrasi Walt Whitman di Masa Kepresidenan Donald Trump" dalam Metahumaniora. Vol. 7 Nomor 2, hlm. 221-233.

Media Bias Fact Check. https://mediabiasfactcheck.com/new-york-times/ (Diakses 30 Nov 2019).

Media Bias Fact Check. https://mediabiasfactcheck.com/reuters/(Diakses 26 Desember 2019).

Media Bias Fact Check. https:/ / mediabiasfactcheck.com/washington-post/(Diakses 26 Desember 2019). 
Media Bias Fact Check. https://mediabiasfactcheck.com/washingtontimes/(Diakses 26 Desember 2019).

Roggenkamp, Karen. 2005. Narrating the News: New Journalism and Literary Genrein Late Nineteenth-CenturyAmerican Newspapers and Fiction. Kent, Ohio: The Kent State University Press.

Sargent, Greg. 2019. “The Scope of Trump's Corruption is Mind-boggling: New DevelopmentsShow How" dalam The Washington Post. https://www.washingtonpost.com/opinions/2019/11/05/scope-trumpscorruption-is-mind-boggling-new-developments-show-how / (Diakses 30 Nov 2019).

Stack, Liam dan Aimee Ortiz. 2019. "What is a Quid Pro Quo?" dalam The New York Times. https://www.nytimes.com/2019/11/20/us/politics/quid-proquo.html. (Diakses 26 Desember 2019).

Teachout, Zephyr. 2014. Corruption in America: From Benjamin Franklin's Snuff Box to Citizens United. Cambridge Massachusets: Harvard University Press. 